Article

\title{
What Is (Fake) News? Analyzing News Values (and More) in Fake Stories
}

\author{
Edson C. Tandoc Jr. ${ }^{1, *}$, Ryan J. Thomas ${ }^{2}$ and Lauren Bishop ${ }^{2}$ \\ ${ }^{1}$ Wee Kim Wee School of Communication and Information, Nanyang Technological University, 637718, Singapore; \\ E-Mail: edson@ntu.edu.sg \\ ${ }^{2}$ Missouri School of Journalism, University of Missouri, Columbia, MO 65211, USA; E-Mails: thomasrj@missouri.edu (R.J.T.), \\ laurenkbishop@mail.missouri.edu (L.B.) \\ * Corresponding author
}

Submitted: 9 June 2020 | Accepted: 9 August 2020 | Published: 3 February 2021

\begin{abstract}
'Fake news' has been a topic of controversy during and following the 2016 U.S. presidential election. Much of the scholarship on it to date has focused on the 'fakeness' of fake news, illuminating the kinds of deception involved and the motivations of those who deceive. This study looks at the 'newsness' of fake news by examining the extent to which it imitates the characteristics and conventions of traditional journalism. Through a content analysis of 886 fake news articles, we find that in terms of news values, topic, and formats, articles published by fake news sites look very much like traditionaland real-news. Most of their articles included the news values of timeliness, negativity, and prominence; were about government and politics; and were written in an inverted pyramid format. However, one point of departure is in terms of objectivity, operationalized as the absence of the author's personal opinion. The analysis found that the majority of articles analyzed included the opinion of their author or authors.
\end{abstract}

\section{Keywords}

content analysis; disinformation; fake news; inverted pyramid; news values; objectivity; traditional news

\section{Issue}

This article is part of the issue "Dark Participation in Online Communication: The World of the Wicked Web" edited by Thorsten Quandt (University of Münster, Germany).

(C) 2021 by the authors; licensee Cogitatio (Lisbon, Portugal). This article is licensed under a Creative Commons Attribution 4.0 International License (CC BY).

\section{Introduction}

'Fake news' became a topic of controversy during and following the 2016 U.S. presidential election. False stories, such as those reporting that the Catholic Pope had endorsed Donald Trump or that Hillary Clinton had authorized the sale of weapons to a terror group, went viral on social media. The phenomenon has called into question the responsibilities of social media giants like Facebook in providing a platform where misinformation can spread quickly (Carlson, 2018; Johnson \& Kelling, 2018) while several governments across the world have considered legislative interventions to address the spread of fake news (Haciyakupoglu, Hui, Suguna, Leong, \& Rahman, 2018; Katsirea, 2018; Tambini, 2017).

Fake news stands in contrast to 'real news,' which is produced by journalists who have long commanded an important gatekeeping role in deigning events as newsworthy and in separating fact from falsehood. Journalism's normative standing does not appear out of thin air but is the result of norms and routines built up over time, into which new entrants are socialized. Such norms and routines help maintain journalism's epistemic authority as a reliable arbiter of what is true and what is not (Carlson, 2017). Simply, this is what helps journalism be believed. It follows, then, that 'fake news' producers would imitate the conventions of 'real news' to leech off of journalism's authority and convince readers that the material presented to them is an authentic account.

This seems a logical presumption, but does it hold true? There has already been ample research on fake news (for a review, see Tandoc, 2019) and, in particular, its 'fakeness,' taking into account the motivations of its producers, its conceptual contours, and its relation- 
ship with other forms of deceptive communication (see, e.g., Allcott \& Gentzkow, 2017; Finneman \& Thomas, 2018). However, there are far fewer works looking at the content characteristics that make 'fake news' look like 'real news.' Mourão and Robertson (2019) analyzed articles published during the 2016 election season in the U.S. by 50 American websites that have been labeled as fake news sites, finding that such articles, many of which were not outright falsehoods, generally "employed moderate levels of sensationalism, clickbait, misleading content and partisan bias" (p. 2090). But what about the extent to which fake news comports with established journalistic conventions? While many studies have focused on the 'fakeness' of fake news, fewer have examined its 'newsness.' Such an inquiry would illuminate the extent to which 'fake news' stories incorporate elements of 'news' into their design and thus draw on those elements as markers of authority. Therefore, this study examines the content characteristics of fake news stories through a content analysis of articles from identified fake news sites in the U.S.

\section{Literature Review}

\subsection{Fake News in Context}

Legacy journalism has been beset by a series of intersecting challenges to its legitimacy, from the diffusion of technologies of content creation to economic tumult to collapsing public trust (Carlson, 2020; Tong, 2018). Meanwhile, a growing number of people consume news via social media (Gottfried \& Shearer, 2016), eroding the relationship between traditional journalism organizations and their audiences due to the insertion of a mediator, allowing for the rapid diffusion of information with little regard to its veracity. Fake news, then, is emblematic of a collapse of journalistic sensemaking authority and "highlights the erosion of long-standing institutional bulwarks against misinformation in the Internet age" (Lazer et al., 2018, p. 1094). In the U.S., these events occur against a backdrop of political polarization, where partisanship influences how people respond to messages (Nyhan \& Reifler, 2010). This is itself layered onto a political culture characterized by relatively easy uptake of conspiracy theories (Oliver \& Wood, 2014). The result of these trends, it has been argued, is that "we are now facing a situation in which a large share of the populace is living in an epistemic space that has abandoned conventional criteria of evidence, internal consistency, and fact-seeking" (Lewandowsky, Ecker, \& Cook, 2017, p. 360).

\subsection{Fakeness and Newsness}

The term 'fake news' is not new. It has, for example, been used to refer to the political satire of figures like Jon Stewart and Stephen Colbert, who have approximated the conventions of broadcast news (and, in
Colbert's case, partisan punditry) for comedic effect (Baym, 2005; Borden \& Tew, 2007). The underlying concept of deceptive mass communications is also, of course, not a new phenomenon. From the colonial era to the 'professionalization' period of journalism in the early 20th century, the journalists of the day would routinely use hoaxes, sensationalism, and exaggeration as a means of selling newspapers (Fedler, 1989; Finneman \& Thomas, 2018).

Fake news is a complex and somewhat controversial concept due to wide variation in the way it is used in public discourse. It is notoriously difficult to define, drawing hoaxes, conspiracy theories, state-sponsored propaganda, partisan-slanted information, manipulated content, satire, and parody into its orbit (Tandoc, Lim, \& Ling, 2018). Scholars have attempted to navigate this terrain by offering definitions of the concept. Such definitions have included "the intentional deception of a mass audience by nonmedia actors via a sensational communication that appears credible but is designed to manipulate and is not revealed to be false" (Finneman \& Thomas, 2018, p. 358); "information that has been deliberately fabricated and disseminated with the intention to deceive and mislead others into believing falsehoods or doubting verifiable facts" (McGonagle, 2017, p. 203); and "news articles that are intentionally and verifiably false, and [that] could mislead readers" (Allcott \& Gentzkow, 2017, p. 213).

In their analysis of the definitions provided to date, Tandoc et al. (2018) demonstrate how the different conceptualizations offered vary in two dimensions: level of facticity and intent. With regard to facticity, while satire and parodies use deception for the main purpose of humor, propaganda and manipulation mainly seek to deceive. Satire mimics and makes fun of the news but ultimately still depends on facts, while parodies rely on fictitious accounts for humor. The intent behind the production of fake news also vary. When outrageous headlines trick readers into clicking a story or if they get drawn to a particular story and visit the page, their clicks get converted into advertising dollars; this is a financial motive. This seems to be what motivated some Macedonian teenagers to create fake news websites and produce fake news articles; their earnings from their fake election stories dwarfed the Macedonian average monthly salary (Subramanian, 2017). By contrast, an ideological motive would be to intentionally muddy public discourse or discredit particular personalities or institutions in order to advance (or prevent) particular political outcomes. For example, Russian forces marshalled a sophisticated disinformation operation in fulfilment of their strategic aims (Haigh, Haigh, \& Kozak, 2018).

What is noteworthy is the extent to which existing definitions of fake news focus on its 'fakeness' that is, its degree of facticity and the intent behind its production-while far less attention has been afforded to its 'newsness' - the extent to which it imitates established journalistic conventions, using them to convey 
truthfulness. For example, Finneman and Thomas (2018) note that fake news "appears credible" (p. 358) but how, precisely, does it appear to be so? If fake news is "fabricated information that mimics news media content in form but not in organizational process or intent" (Lazer et al., 2018, p. 1094) then what exactly is this form? The literature to date has not explored these questions. To understand the newsness of fake news, we need to first examine the newsness of real news.

\section{3. 'Real News' and its Routines}

Journalism is identifiable by its adherence to a set of routines, which are "patterned, repeated practices, forms, and rules that media workers use to do their jobs" and "practical responses to the needs of media organizations and workers" that "optimize the relationships between an organization and its environment" (Shoemaker \& Reese, 2014, pp. 165, 168). These routines not only make the process of newswork more efficient but also help maintain journalism's authority as a reliable arbiter of what is true and what is false (Carlson, 2017).

Though scholarship emphasizes how fake news stories are built on falsehoods, the assumption that fake news stories mimic real news is often taken for granted. This is an important assumption to test, as it has implications for how we understand and deal with fake news as a social problem. One way to examine to what extent fake news articles mimic real news is to compare them based on attributes that characterize traditional news, on top of being based on facts. Defining news is not easy. Schudson (2018) defines it as "usually" referring to "novel information about relatively recent affairs" (p. 999). News writing textbooks also usually refer to news as an account of a recent, significant, extraordinary, and interesting event (e.g., Harcup, 2015; Kershner, 2005; Richardson, 2007). But aside from what news is about, conceptualizations of what news is have also included conventions on how it is produced and communicated; for example, news is marked by several contentrelated conventions, such as the use of an inverted pyramid format (e.g., Harcup \& O'Neill, 2017; Thomson, White, \& Kitley, 2008; Vos, 2002).

In comparing real news with fake news based on some content markers of real news, this study is modelled on prior work that has looked at emergent journalistic actors that, in producing news, adopt the norms and routines of the 'mainstream,' rather than actively departing from or challenging them. For example, Tandoc (2018) examined the extent to which BuzzFeed, a relative newcomer to the journalistic field, abided by the same set of rules as The New York Times, long regarded as an industry leader and national newspaper of record in the U.S., finding that, with regard to the presence of particular news values, the dominant topic, news format, and use of objectivity, BuzzFeed behaved very much like a traditional news organization. This current study adopts this framework and considers the following as representative (albeit not definitive) markers of 'real news,' which can be used to measure the 'newsness' of fake news: News values, news topic, news format, and objectivity.

\subsubsection{News Values}

One way that journalism can be distinguished from other forms of writing is through journalists' use of news values, which refer to journalists' "shared operational understanding" that informs "the mediated world that is presented to news audiences" (Harcup \& O'Neill, 2017, p. 1470). These criteria for determining newsworthiness are "passed down to new generations through a process of training and socialization" (Harrison, 2006, p. 153). Though different news organizations may prioritize different news values according to market orientation, national context, and the degree of journalistic autonomy, it suffices to say that the identification or combination of any mix of news values serves as a cue to the newsworthiness of a story, and the more criteria an event satisfies, the more likely it is to become news (Harcup \& O'Neill, 2017).

No taxonomy of news values can be definitive. We focus here on four specific news values that recur in empirical studies of traditional news content and in metaanalyses of the literature (see, e.g., Harcup \& O'Neill, 2017; Shoemaker \& Reese, 2014). These are the news values of timeliness, negativity, prominence, and impact. Though proximity is a commonly studied news value, it is operationalized in terms of the issue or event's proximity to the newsroom; since most fake news sites come and go and operate anonymously, it is difficult to ascertain their respective geographic locations.

The news value of timeliness pertains to the recency of the information and "responds to the impetus of the news being recent and up-to-date" (Kilgo, Lough, \& Riedl, 2020, p. 270). Timeliness is not only a long-established news norm, but also one that is embraced by emergent journalistic actors, such as BuzzFeed, that incorporate it into their reporting (Tandoc, 2018). Negativity refers to 'bad news' stories possessing unpleasant undertones that disrupt the normal state of affairs, such as those involving conflict or tragedy (Harcup \& O'Neill, 2017). The news value of prominence refers to the involvement of prominent individuals or organizations and has been found to be key to the 'shareworthiness' of content on social media (García-Perdomo, Salaverría, Kilgo, \& Harlow, 2018; Kilgo et al., 2020). Finally, impact relates to the significance, magnitude, or effects of the issue or event at hand in terms of their scale, reflecting how news stories spotlight "the most severe storms, the most damaging fires, the most deadly accidents, the most important speeches, and the most interesting organizations because these are likely to affect the most readers and viewers and have the most serious consequences" (Fedler, Bender, Davenport, \& Drager, 2001, p. 110). Working from the premise that fake news tries to mimic traditional news, we ask: 
RQ1: What percentage of articles published by fake news sites contain the following news values: a) timeliness, b) negativity, c) prominence, and d) impact?

\subsubsection{Topic}

The news production process is also traditionally characterized by the classification of stories by topic, such as politics, crime, business, health, or entertainment. This classification affects how stories are organized in a newspaper or online (Dick, 2011) and shapes stories' shareability (García-Perdomo et al., 2018). There are normative judgments associated with this, where stories about politics and government are treated as possessing greater normative import than other kinds of journalism (Schultz, 2007). Indeed, research by Tandoc (2018) found that both BuzzFeed and The New York Times published stories about government or politics most frequently, followed by crime or terrorism stories. Thus, we also ask:

RQ2: What news topics do fake news sites write most frequently about?

\subsubsection{News Format}

Analyses of journalistic content have also focused on the format of journalistic prose. The inverted pyramid style, where the most important information is placed at the top, dominates mainstream news reporting. This is likely due to its normative purchase, being associated with objectivity due to the way it standardizes the presentation of news content as an authoritative account of events (Thomson et al., 2008; Vos, 2002). Though alternatives exist, such as the narrative style common to literary journalism (see Johnston \& Graham, 2012) or emergent forms such as the 'listicle' (see Tandoc, 2018), the inverted pyramid persists in the U.S. as a dominant format of organizing news, so much so that the format itself can trigger heuristics that affect the perceived credibility of a message (Sundar, 2008). It follows, therefore, that fake news producers would attempt to imitate this style of narrative to appear authoritative and thus be believed. Thus:

RQ3: What percentage of articles published by fake news sites use the inverted pyramid format?

\subsubsection{Objectivity}

Finally, a common marker of traditional journalism in the U.S. is the use of objectivity, which casts journalists in the role of impartial scientists pursuing the evidence wherever it leads and demonstrates "faith in 'facts,' a distrust of 'values,' and a commitment to their segregation" (Schudson, 1978, pp. 4-5). As a signaling mechanism, objectivity implies that journalists have obtained "all relevant information" and vetted it to "determine why accounts conflict and which more accurately reflect reality" (Ryan, 2001, p. 4). Objectivity is frequently cited as being at the root of journalism's epistemic authoritythat is, its credibility as the arbiter of what is factual (Carlson, 2017).

Though opinion remains a prominent part of U.S. journalism (e.g., opinion columns, public affairs talk shows), within the output of mainstream news organizations it is compartmentalized away from news and given its own section. This is both a literal and symbolic separation, reinforcing the norm that opinion ought not intrude into news reporting (Thomas, 2018). Accordingly, empirical studies of news content have operationalized objectivity as the absence of opinion (see, e.g., Lawrence, Molyneux, Coddington, \& Holton, 2014; Molyneux, 2015; Tandoc, 2018; Tandoc \& Thomas, 2017). It follows, then, that fake news producers may seek to take advantage of this journalistic credibility in order to be believed, by putting on a semblance of objectivity. Therefore:

RQ4: What percentage of articles published by fake news sites exclude personal opinion of the author?

\section{Method}

\subsection{Sampling}

Seeking to examine the extent to which fake news mimics real news, this study is based on a content analysis of 886 articles from 23 fake news sites. Sampling took several stages. First, we built a list of fake news sites by relying on lists published by news and entertainment site BuzzFeed and fact-checking sites PolitiFact and FactCheck. BuzzFeed's list was based on "the topperforming Facebook content from 96 fake news websites...built up over the past two years of covering this topic" and cross-referenced against a chart by Hoaxy (a tool that visualizes the spread of articles online) resulting in "a more comprehensive list of pure fake news sites" (Silverman, 2016, para. 4). PolitiFact's list was based on "every website on which [they had] found deliberately false or fake news stories since we started working along with Facebook" (PolitiFact, 2017, para. 5). FactCheck offered "a list of websites that have posted deceptive content" (FactCheck, 2017, para. 1). As has been noted (e.g., Mourão \& Robertson, 2019), differences in the ways that fake news is conceptualized and measured result in challenges in this line of empirical work. None of the lists we draw upon claimed to be exhaustive but are indicative of efforts at legitimate news and fact-checking organizations to catalog fake news sites. A combined list based on these three sources included 230 fake news sites.

Next, we randomly selected 23 sites from the list, representing $10 \%$ of the listed fake news sites. Then, for each randomly selected site, we collected links to all their published articles between February 28, 2017, and February 28, 2018, using BuzzSumo, a social media marketing online tool that allows tracking of online content and their social media engagement metrics that has 
been used by studies on social media content (see, e.g., Cadman \& Galvin, 2019; Sommariva, Vamos, Mantzarlis, Đào, \& Martinez Tyson, 2018; Waszak, KasprzyckaWaszak, \& Kubanek, 2018). This yielded 9,915 articles, from which we randomly selected 992 articles, again representing $10 \%$ of the sample. Some of the links, however, were no longer active when we conducted the study, leaving the final study with a total of 886 articles for content analysis. We analyzed the selected articles by reading them on the actual webpage where they were published-that is, we clicked on the links we collected from BuzzSumo to access the articles. We focused on coding the article's main text and excluded any complementary materials, such as accompanying visuals. Thus, the unit of analysis for this study is the article's main text. Due to the transitory nature of fake news sites, our sample is only representative of the fake news sites represented in these lists and not of the continuously evolving fake news ecosystem in the U.S.

\subsection{Variables}

Two coders were trained using a content analysis manual adapted from an earlier study (Tandoc, 2018). The manual included measures of what previous studies have considered as markers of traditional news. Following three training sessions, two practice coding sessions, and acceptable intercoder reliability values, the actual coding began with each coder independently coding half of the sample. The first practice coding involved 20 recent fake news articles collected from a fake news site not included in the sample. The purpose of the first practice coding was to introduce the coders to the process of coding as well as obtain initial feedback on the coding manual. The second practice coding involved 20 randomly selected fake news articles from the population of articles where the actual sample came from. These 20 articles were excluded from the final sample.

\subsubsection{News Values}

The articles were coded for the presence or absence of four news values common in the literature: timeliness, negativity, prominence, and impact. Timeliness refers to whether the article was about something recent, timely or seasonal. Negativity refers to whether the article focused on the negative aspects of the issue or event. Prominence refers to whether the article involved wellknown or elite sources, either individuals or organizations. Finally, impact refers to whether the issue or event in the article has high significance in terms of its effects or consequences to the population. The coders consistently coded for news values (Krippendorf's $\alpha=0.74$ ).

\subsubsection{News Topics}

The articles were also coded for their main story topic. Drawing on an integrated list of recurrent topics iden- tified in the literature (Becker, 2009; Becker, Lowrey, Claussen, \& Anderson, 2000; Magin \& Maurer, 2019; Maguire, 2014; Schierhorn, Endres, \& Schierhorn, 2001; Sjøvaag, 2015; Tandoc, 2018), stories were coded if the main story topic was about: government and politics; crime or terrorism; economy and business; education; environment and energy; transportation and public works; accidents and disasters; science, health, and technology; religion; social problems and human rights; human interest; sports; or entertainment. Intercoder reliability agreement was initially low (Krippendorf's $\alpha=0.22$ ), which prompted additional coder training on this measure until both coders had a common and confident understanding of how the topic categories were to be coded. Subsequent intercoder testing showed the intercoder reliability score to be close to the acceptable range (Krippendorf's $\alpha=0.64$ ).

\subsubsection{News Format}

The articles were coded for their format, or how the story was written or presented. It could be any of these commonly used news formats, as deduced from the literature: inverted pyramid, listicle, chronology, reversed chronology, or narrative. Since this was a straightforward measure, the coders achieved perfect agreement for this category.

\subsubsection{Objectivity}

Finally, the articles were coded for the presence or absence of the journalist's opinion on the subject matter or issue. For an article to be coded as having the opinion of the journalist, the inclusion of personal opinion must be explicit. For example, a fake news article wrongly claimed eight witnesses of the Las Vegas mass shooting in October 2017 had suspiciously died, talked about how "the official narrative stinks so badly" and described as "staggering" the number of witnesses who "have died in suspicious circumstances"; these claims have been debunked by fact-checking organizations, such as Snopes.com. In this article, the use of value-laden adjectives in sentences not attributed to any source explicitly includes personal judgments of the author. Implicit inclusion of opinion, such as the choice of particular sources over others, is therefore not captured in this variable. This was also coded as a binary nominal variable (opinion present/opinion absent), with an acceptable intercoder reliability score (Krippendorf's $\alpha=0.87$ ).

\section{Findings}

\subsection{News Values}

RQ1 asked what percentage of articles published by fake news sites contain the news values of a) timeliness, b) negativity, c) prominence, and d) impact. The analysis showed that $98.6 \%$ of the articles analyzed included the 
news value of timeliness; $89.2 \%$ included the news value of negativity; $79.7 \%$ included the news value of prominence; but only $32 \%$ included the news value of impact. In comparison, a previous study that analyzed the content of The New York Times (Tandoc, 2018), whose framework we have adopted for this study, had found that majority of its news articles included the news values of timeliness $(72.7 \%)$, negativity $(74.5 \%)$, prominence (64.2\%), and impact (59\%). Therefore, in terms of the news values of timeliness, negativity, and prominence, articles from fake news sites seem to mimic real news articles (see Table 1). However, most of the articles analyzed do not have the news value of impact, focusing on trivial things, such as a fake news article reporting that a woman was hospitalized after she was beaten with dildos.

Table 1. News values (\%).

\begin{tabular}{lcr}
\hline & Yes & No \\
\hline Timeliness & 98.6 & 1.4 \\
Negativity & 89.2 & 10.8 \\
Prominence & 79.7 & 20.3 \\
Impact & 32.3 & 67.7 \\
\hline
\end{tabular}

\subsection{News Topic}

RQ2 asked what topics are most frequently written about by fake news sites. The analysis found that $51.6 \%$ of the articles analyzed were about government or politics (see Table 2). This was followed by crime or terrorism (19.5\%) and by science, health or technology (10.3\%). In comparison, among the most common topics reported by The New York Times based on a previous study were government or politics (31.6\%); crime or terrorism (27.1\%); and science, health, or technology (8.2\%; Tandoc, 2018). However, many of political or crime-related stories we analyzed focused on trivial matters, potentially aimed at fanning political polarization rather than disseminating important information. For example, a fake news article reported that a leaked email revealed that "Michelle Obama admits she hates Hillary Clinton." While this is considered a story about politics, it is an 'issue' that does not involve or affect the population.

Table 2. News topic.

\begin{tabular}{lc}
\hline Topic & Percentage \\
\hline Government/Politics & 51.6 \\
Crime/Terrorism & 19.5 \\
Science/Health/Technology & 10.3 \\
Sports/Entertainment/Arts & 6.9 \\
Accidents/Disasters & 3.7 \\
Economy/Business & 2.5 \\
Public Services & 1.6 \\
Religion/Churches & 1.5 \\
Environment/Climate Change & 1.1 \\
\hline
\end{tabular}

\subsection{News Format}

RQ3 asked about the most commonly used news format by fake news sites. The analysis found that $98.8 \%$ of the articles analyzed used the inverted pyramid format (see Table 3). In comparison, Tandoc (2018) found that $70.8 \%$ of the news articles published by The New York Times used inverted pyramid.

Table 3. News format.

\begin{tabular}{lc}
\hline Format & Percentage \\
\hline Inverted pyramid & 98.8 \\
Listicle & .4 \\
Chronology & .1 \\
Narrative & .7 \\
\hline
\end{tabular}

\subsection{Objectivity}

Finally, RQ4 asked what percentage of the articles published by fake news sites adhered to the standard of objectivity by excluding any personal opinion of the author. The analysis found that only $35.7 \%$ of the articles analyzed excluded personal opinion, while the majority, or $64.3 \%$, included the personal opinion of the author or authors (see Table 4). For example, a trivial fake news article that claimed rapper Jay-Z was caught "shapeshifting" by passengers in a United Airlines flight included references to how the airline was desperate to avoid another scandal and engaged in steps to cover-up the incident. Such comment was not attributed to any source. By contrast, a content analysis of news articles published by The New York Times found that $75.8 \%$ of its articles excluded journalists' opinions (Tandoc, 2018).

Table 4. Objectivity.

\begin{tabular}{lc}
\hline Presence of Opinion & Percentage \\
\hline No & 35.7 \\
Yes & 64.3 \\
\hline
\end{tabular}

\section{Discussion}

This study set out to explore the extent to which fake news content imitates the conventions of traditional, 'real' news. Where previous studies have focused on the 'fakeness' of fake news, this study focused on its 'newsness.' Guided by previous studies that mapped out markers of traditional news, this study analyzed articles published by fake news sites based on news values, topic, format, and objectivity. The study found that in terms of news values, topic, and format, the articles analyzed look very much like traditional news. The majority of the articles we studied included the news values of timeliness, negativity, and prominence; were about government and politics; and were written in an inverted pyramid format. However, one point of departure is in 
terms of objectivity, operationalized as the absence of the author's personal opinion. The analysis found that the majority of the articles included the personal opinion of their author or authors. The news value of impact was also not very common among fake news sites, which seem to focus a lot on concocting trivial stories.

\subsection{Implications}

By identifying the content characteristics common across stories published by fake news sites, this study has provided empirical data to inform what may have previously been assumed. Our findings, overall, suggest that fake news producers imitate the conventions of traditional news. This mimicry leeches off journalism's epistemic authority for deceptive ends. Put another way, for fake news producers, news is simply the means, but deception is the ends. Overall, this reinforces the association between journalistic routines and content conventions and journalism's epistemic authority. By mimicking these content conventions, from writing style and format to news values, fake news producers exploit journalism's social standing. This lends support to the assumption that fake news, as a specific form of deliberate attempts at disinformation, refers to articles devoid of factual basis deliberately packaged to look like news in order to deceive.

The findings of this study help to illuminate what content characteristics of real news fake news producers are appropriating to give their outputs a semblance of truthfulness or even legitimacy. An underlying ideological motivation, such as sowing distrust on a government investigation of a mass shooting, can be propagated even in the absence of facts as fake news producers can package a false claim (e.g., suspicious deaths of witnesses that signal a cover-up) supporting their underlying motivation (e.g., sow distrust in the government) with content characteristics associated with real news (e.g., reference to a timely event, focus on a negative aspect, peg to a prominent topic, use of inverted pyramid, among others) to turn a false narrative into one that looks like a real, legitimate news story. Employed in a regular fashion, for both completely false as well as real but incomplete or sensationalized articles, the appropriation of content characteristics of real news can potentially don a website with a cloak of legitimacy, at least for those readers its articles are able to mislead. Thus, the 'newsness' of fake news helps not only specific fake news articles to deceive, but also potentially the websites and social media accounts that regularly publish them.

However, the analysis also uncovered some areas of departure, the most notable of which is in terms of objectivity. This study found that the majority of the articles analyzed included the opinion of their author or authors. It may well be that the absence of objectivity explains why fake news is so potent. By explicitly appealing to readers' existing predispositions through the inclusion of similar opinions by the author or authors, fake news arti- cles increase their resonance, legitimacy, and believability among a group of readers, a phenomenon known as confirmation bias (Taber \& Lodge, 2006). This could also reflect the prominence of partisan punditry and commentary in the media landscape (see, e.g., Levendusky, 2013) and the acceptance of opinion as a news value. In their study of what young adults consider news, Armstrong, McAdams, and Cain (2015) found that "consumers may have come to expect-and even seek outsubjective, opinion-laden news to help them make sense of prominent, impactful, and controversial events and issues" (p. 95). Given these conditions, it may be the case that fake news producers are cognizant of changes in how journalism is being produced, received, and evaluated and are taking advantage of such shifts.

Of particular interest is the finding that the articles we studied used the inverted pyramid style of prose while departing from the objectivity norm, as the two have typically been treated as congruent (Thomson et al., 2008; Vos, 2002). It may be the case that the association between the two is weakening, although it is beyond the scope of this study to establish this with empirical certainty. A plausible explanation may lie in the intent of the fake news producers, who may have observed that the inverted pyramid remains prevalent as a 'standard' way of organizing news presentation while the objectivity norm may be less salient to the goal of deepening partisan attitudes in targeted populations. Another explanation may lie in the nature of the sample, which focused on articles from fake news sites in the U.S., a country characterized by growing political polarization, declining trust in journalism along partisan lines, and the prominence of opinionated and partisan media content (Newman, \& Fletcher, Schulz, Andı, \& Nielsen, 2020). These intersecting and mutually reinforcing factors represent a context where fake news producers feel that content displaying a high degree of partisanship is likely to gain traction.

Fake news is a problematic term, and one could argue that persisting in its use-in other words, deigning such content as "news" to begin with-mistakenly deigns it with legitimacy. That the term has been taken up by politicians to describe unfavorable reporting (Lischka, 2019) makes this terrain yet more complicated. However, it remains a worthwhile endeavor to examine the extent to which those that pass off deceptive information as news mimic the conventions of real news for deceptive ends. This provides more precision in determining how fake news approximates 'newsness' in content if not in ethics.

\subsection{Limitations and Directions for Future Research}

The findings of this study have to be understood in the context of several limitations. To be sure, a content analysis can only analyze manifest content and not the motivations and routines behind content patterns. Future studies should look into practices that lead to the content 
patterns this study has uncovered. If fake news looks like real news, what routines do fake news producers follow to construct fake news outputs and how do those routines compare with those of journalists? Granted, pursuing such a line of research may be replete with practical challenges.

While the lists of fake news sites we used for sampling are comprehensive, they are not exhaustive, since fake news sites come and go. Therefore, our findings cannot be generalized to the whole population of fake news in the U.S.; at most, our findings represent the fake news sites in the lists we used at the time of data collection. It is possible that fake news has evolved since then, and future studies can build on our findings to continue tracking how fake news evolves. We also focused our sampling on websites labeled as fake news sources, similar to what a previous study conducted (Mourão \& Robertson, 2019), which had found that these sites do not exclusively published falsehoods but also truthful accounts. Our study, however, focused on examining the use of journalistic conventions rather than reliance on facts per se.

Finally, we focused on articles published by fake news sites identified in the U.S., and we should be wary of suggesting that what would pertain to one context would pertain elsewhere, given differences in political and media contexts across systems. Fake news is a global problem, and it is important to study it in other national contexts. If fake news packages fake information to look like real news, how does it look like in media contexts whose form and substance are different from that of U.S. journalism?

Despite these limitations, we hope our findings contribute to a more nuanced understanding of fake news. The findings of this current study not only provide empirical support for the assumption that fake news mimics real news to leech off journalism's social legitimacy and authority, but also raise questions for future studies. For example, an interesting finding is that after politics and crime, the topics of science, technology and health are the third most frequent subjects of fake news articles. This has implications for how the public understands, or misunderstands, already complex but important issues involved in science, technology, and health (such as climate change, vaccinations, and Covid-19 remedies). Furthermore, as this study showed how similar fake news is to real news when it comes to content structure, such content characteristics no longer suffice as demarcations between real and fake news. They should no longer be held as authenticity cues. Indeed, such content markers are what fake news producers exploit to deceive readers. For example, quoting prominent personalities has long been associated with newsworthiness, but it should not be used as an automatic measure of truth or indicator of trustworthiness, since fake news can also attribute madeup quotes to real people. Newsworthiness as a concept must be revisited, and its heuristic value for journalists and audiences questioned. Future studies should explore how real news can distinguish itself from fake news and how their results can be communicated to readers to equip them with skills to distinguish what is real from what is fake, and to value the former over the latter.

\section{Acknowledgments}

The authors are grateful for the work of the data coders. The first author's work on this project was also supported by a Tier 1 Academic Grant from the Singapore Ministry of Education.

\section{Conflict of Interests}

The authors declare no conflict of interests.

\section{References}

Allcott, H., \& Gentzkow, M. (2017). Social media and fake news in the 2016 election. Journal of Economic Perspectives, 31(2), 211-236.

Armstrong, C. L., McAdams, M. J., \& Cain, J. (2015). What is news? Audiences may have their own ideas. Atlantic Journal of Communication, 23(2), 81-98.

Baym, G. (2005). The Daily Show: Discursive integration and the reinvention of political journalism. Political Communication, 22(3), 259-276.

Becker, L. (2009). Employment. In C. H. Sterling (Ed.), Encyclopedia of journalism (pp. 514-519). Thousand Oaks, CA: Sage.

Becker, L., Lowrey, W., Claussen, D., \& Anderson, W. (2000). Why does the beat go on? Newspaper Research Journal, 21(4), 2-16.

Borden, S. L., \& Tew, C. (2007). The role of journalist and the performance of journalism: Ethical lessons from "fake" news (seriously). Journal of Mass Media Ethics, 22(4), 300-314.

Cadman, K., \& Galvin, J. P. (2019). Graft versus host disease: An analysis of Internet and social network activity and engagement. Biology of Blood \& Marrow Transplantation, 25(3), 81-82.

Carlson, M. (2017). Journalistic authority: Legitimating news in the digital era. New York, NY: Columbia University Press.

Carlson, M. (2018). Facebook in the news: Social media, journalism, and public responsibility following the 2016 Trending Topics controversy. Digital Journalism, 6(1), 4-20.

Carlson, M. (2020). Fake news as an informational moral panic: The symbolic deviancy of social media during the 2016 U.S. Presidential election. Information, Communication, \& Society, 23(3), 374-388.

Dick, M. (2011). Search engine optimization in UK news production. Journalism Practice, 5(4), 462-477.

FactCheck. (2017). Misinformation directory. FactCheck. Retrieved from https://www.factcheck.org/2017/ 07/websites-post-fake-satirical-stories

Fedler, F. (1989). Media hoaxes. Ames, IA: lowa State University Press. 
Fedler, F., Bender, J. R., Davenport, L. D., \& Drager, M. W. (2001). Reporting for the media (7th ed.). San Diego, CA: Harcourt College.

Finneman, T., \& Thomas, R. J. (2018). A family of falsehoods: Deception, media hoaxes, and fake news. Newspaper Research Journal, 39(3), 350-361.

García-Perdomo, V., Salaverría, R., Kilgo, D. K., \& Harlow, S. (2018). To share or not to share: The influence of news values and topics on popular social media content in the United States, Brazil, and Argentina. Journalism Studies, 19(8), 1180-1201.

Gottfried, J., \& Shearer, E. (2016). News use across social media platforms 2016. Pew Research Center. Retrieved from https://www.journalism.org/2016/ 05/26/news-use-across-social-media-platforms2016

Haciyakupoglu, G., Hui, J. Y., Suguna, V. S., Leong, D., \& Rahman, M. F. B. A. (2018). Countering fake news: A survey of recent global initiatives. Singapura: S. Rajaratnam School of International StudiesNanyang Technological University. Retrieved from https://www.think-asia.org/handle/11540/8063

Haigh, M., Haigh, T., \& Kozak, N. I. (2018). Stopping fake news: The work practices of peer-to-peer counter propaganda. Journalism Studies, 19(14), 2062-2087.

Harcup, T. (2015). Journalism principles and practice. Thousand Oaks, CA: Sage.

Harcup, T., \& O'Neill, D. (2017). What is news? News values revisited (again). Journalism Studies, 18(12), 1470-1488.

Harrison, J. (2006). News. New York, NY: Routledge.

Johnson, B. G., \& Kelling, K. (2018). Placing Facebook: 'Trending,' 'Napalm Girl,' 'fake news' and journalistic boundary work. Journalism Practice, 12(7), 817-833.

Johnston, J., \& Graham, C. (2012). The new, old journalism: Narrative writing in contemporary newspapers. Journalism Studies, 13(4), 517-533.

Katsirea, I. (2018). 'Fake news': Reconsidering the value of untruthful expression in the face of regulatory uncertainty. Journal of Media Law, 10(2), 159-188.

Kershner, J. W. (2005). The elements of news writing. Boston, MA: Pearson Allyn and Bacon.

Kilgo, D. K., Lough, K., \& Riedl, M. J. (2020). Emotional appeals and news values as factors of shareworthiness in ice bucket challenge coverage. Digital Journalism, 8(2), 267-286.

Lawrence, R. G., Molyneux, L., Coddington, M., \& Holton, A. (2014). Tweeting conventions: Political journalists' use of Twitter to cover the 2012 Presidential campaign. Journalism Studies, 15(6), 789-806.

Lazer, D. M. J., Baum, M. A., Benkler, Y., Berinsky, A. J., Greenhill, K. M., Menczer, F., . . . Zittrain, J. L. (2018). The science of fake news. Science, 359(6380), 1094-1096.

Levendusky, M. (2013). How partisan media polarize America. Chicago, IL: University of Chicago Press.

Lewandowsky, S., Ecker, U. K. H., \& Cook, J. (2017). Beyond misinformation: Understanding and coping with the "post-truth" era. Journal of Applied Research in Memory \& Cognition, 6(4), 353-369.

Lischka, J. A. (2019). A badge of honor? How The New York Times discredits President Trump's fake news accusations. Journalism Studies, 20(2), 287-304.

Magin, M., \& Maurer, P. (2019). Beat journalism and reporting. In J. F. Nussbaum (Ed.), Oxford research encyclopedia of communication. Retrieved from https://doi.org/10.1093/acrefore/9780190228613. 013.905

Maguire, M. (2014). Advanced reporting: Essential skills for 21st century journalism. New York, NY: Routledge.

McGonagle, T. (2017). 'Fake news': False fears of real concerns. Netherlands Quarterly of Human Rights, 35(4), 203-209.

Molyneux, L. (2015). What journalists retweet: Opinion, humor, and brand development on Twitter. Journalism, 16(7), 920-935.

Mourão, R. R., \& Robertson, C. T. (2019). Fake news as discursive integration: An analysis of sites that publish false, misleading, hyperpartisan and sensational information. Journalism Studies, 20(14), 2077-2095.

Newman, N., \& Fletcher, R., Schulz, A., Andı, S., \& Nielsen, R. K. (2020). Reuters Institute digital news report 2020. Oxford: Reuters Institute for the Study of Journalism. Retrieved from https://reutersinstitute. politics.ox.ac.uk/sites/default/files/2020-06/ DNR_2020_FINAL.pdf

Nyhan, B., \& Reifler, J. (2010). When corrections fail: The persistence of political misperceptions. Political Behavior, 32(2), 303-330.

Oliver, J. E., \& Wood, T. J. (2014). Conspiracy theories and the paranoid style(s) of mass opinion. American Journal of Political Science, 58(4), 952-966.

PolitiFact. (2017, April 20). PolitiFact's guide to fake news websites and what they peddle. PolitiFact. Retrieved from https://www.politifact.com/article/2017/apr/ 20/politifacts-guide-fake-news-websites-and-whatthey

Richardson, B. (2007). The process of writing news: From information to story. Boston, MA: Pearson.

Ryan, M. (2001). Journalistic ethics, objectivity, existential journalism, standpoint epistemology, and public journalism. Journal of Mass Media Ethics, 16(1), 3-22.

Schierhorn, A. B., Endres, F. F., \& Schierhorn, C. (2001). Newsroom teams enjoy rapid growth in the 1990s. Newspaper Research Journal, 22(3), 2-15.

Schudson, M. (1978). Discovering the news: A social history of American newspapers. New York, NY: Basic Books.

Schudson, M. (2018). News. In T. P. Vos \& F. Hanusch (Eds.), The international encyclopedia of journalism studies (pp. 999-1005). Hoboken, NJ: John Wiley \& Sons.

Schultz, I. (2007). The journalistic gut feeling: Journalistic doxa, news habitus, and orthodox news values. Journalism Practice, 1(2), 190-207. 
Shoemaker, P. J., \& Reese, S. D. (2014). Mediating the message in the 21st century: A media sociology perspective (3rd ed.). New York, NY: Routledge.

Silverman, C. (2016, December 30). Here are 50 of the biggest fake news hits on Facebook from 2016. BuzzFeed News. Retrieved from https://www. buzzfeednews.com/article/craigsilverman/top-fakenews-of-2016

Sjøvaag, H. (2015). Hard news/soft news: The hierarchy of genres and the boundaries of the profession. In M. Carlson \& S. C. Lewis (Eds.), Boundaries of journalism: Professionalism, practices, and participation (pp. 101-117). New York, NY: Routledge.

Sommariva, S., Vamos, C., Mantzarlis, A., Đào, L. U. L., \& Martinez Tyson, D. (2018). Spreading the (fake) news: Exploring health messages on social media and the implications for health professionals using a case study. American Journal of Health Education, 49(4), 246-255.

Subramanian, S. (2017, February 2). Inside the Macedonian fake news complex. Wired. Retrieved from https://www.wired.com/2017/02/veles-macedoniafake-news

Sundar, S. S. (2008). The MAIN model: A heuristic approach to understanding technology effects on credibility. In M. J. Metzger \& A. J. Flanagin (Eds.), Digital media, youth, and credibility (pp. 73-100). Cambridge, MA: The MIT Press.

Taber, C. S., \& Lodge, M. (2006). Motivated skepticism in the evaluation of political beliefs. American Journal of Political Science, 50(3), 755-769.

Tambini, D. (2017). Fake news: Public policy responses. London: The London School of Economics and Polit- ical Science. Retrieved from http://eprints.Ise.ac.uk/ 73015

Tandoc, E. C. (2018). Five ways BuzzFeed is preserving (or transforming) the journalistic field. Journalism, 19(2), 200-216.

Tandoc, E. C. (2019). The facts of fake news: A research review. Sociology Compass, 13(9), 1-9.

Tandoc, E. C., Lim, Z. W., \& Ling, R. (2018). Defining 'fake news': A typology of scholarly definitions. Digital Journalism, 6(2), 137-153.

Tandoc, E. C., \& Thomas, R. J. (2017). Readers value objectivity over transparency. Newspaper Research Journal, 38(1), 32-45.

Thomas, R. J. (2018). Advocacy journalism. In T. P. Vos (Ed.), Journalism (pp. 391-413). Berlin: Walter de Gruyter.

Thomson, E. A., White, P. R. R., \& Kitley, P. (2008). 'Objectivity' and 'hard news' reporting across cultures: Comparing the news report in English, French, Japanese, and Indonesian journalism. Journalism Studies, 9(2), 212-228.

Tong, J. (2018). Journalistic legitimacy revisited: Collapse or revival in the digital age? Digital Journalism, 6(2), 256-273.

Vos, T. P. (2002). Newswriting structure and style. In W. D. Sloan \& L. M. Parcell (Eds.), American journalism: History, principles, practices (pp. 296-305). Jefferson, NC: McFarland \& Co.

Waszak, P. M., Kasprzycka-Waszak, W., \& Kubanek, A. (2018). The spread of medical fake news in social media: The pilot quantitative study. Health Policy \& Technology, 7(2), 115-118.

\section{About the Authors}
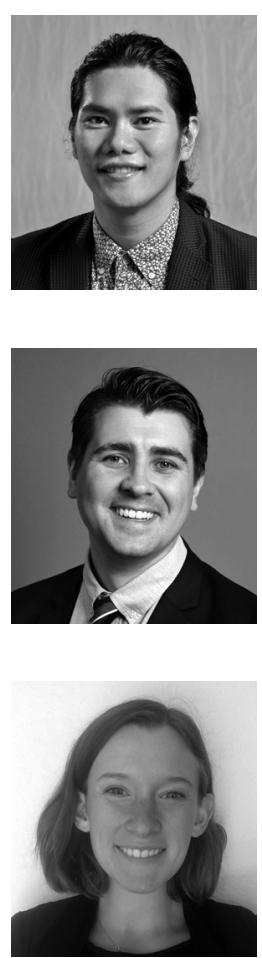

Edson C. Tandoc Jr. (PhD) is an Associate Professor at the Wee Kim Wee School of Communication and Information at Nanyang Technological University, Singapore. His studies have focused on the impact of journalistic roles, new technologies, and audience feedback on the news gatekeeping process. He has also looked at how readers make sense of critical incidents in journalism and take part in reconsidering journalistic norms; and how changing news consumption patterns facilitate the spread of fake news.

Ryan J. Thomas (PhD) is an Associate Professor of Journalism Studies in the Missouri School of Journalism at the University of Missouri. His research program addresses the intersection of journalism ethics and the sociology of news, focusing on journalism amid processes of change: the forces shaping journalism, how journalists make sense of them, and how these changes affect journalism's institutional obligations and role in public life.

Lauren Bishop works at the Grants Pass Daily Courier in Oregon as the City Hall reporter. She graduated from the University of Missouri in 2020 with a BA in Journalism and a BA in Arts in Political Science. 